\title{
A Multivariate Analysis of the Effects of Structural Breaks on Stock Return Volatility Persistence: The Case of the US and Japan
}

\author{
Chikashi Tsuji ${ }^{1}$ \\ ${ }^{1}$ Faculty of Economics, Chuo University, Tokyo, Japan \\ Correspondence: Chikashi Tsuji, Professor, Faculty of Economics, Chuo University, 742-1 Higashinakano, \\ Hachioji-shi, Tokyo 192-0393, Japan. E-mail: mail_sec_low@minos.ocn.ne.jp
}

Received: March 15, 2019

Accepted: April 3, 2019

Online Published: April 7, 2019

doi:10.5430/ijba.v10n3p39

URL: https://doi.org/10.5430/ijba.v10n3p39

\begin{abstract}
This paper quantitatively inspects the effects of structural breaks in stock returns on their volatility persistence by using the stock return data of the US and Japan. More concretely, applying the diagonal BEKK-MGARCH model with and without structural break dummies to the returns of S\&P 500 and TOPIX, we reveal the following interesting findings. (1) First, we clarify that for both the US and Japanese stock returns, the values of the GARCH parameters, namely, the values of the volatility persistence parameters in the diagonal BEKK-MGARCH models decrease when we include the structural break dummies in the models. (2) Second, we further find that interestingly, during the Lehman crisis in 2008, the estimated time-varying volatilities from the diagonal BEKK-MGARCH model with structural break dummies are slightly higher than those from the no structural break dummy model. (3) Third, we furthermore reveal that also very interestingly, the estimated time-varying correlations from the diagonal BEKK-MGARCH model with no structural break dummy are slightly higher than those from the structural break dummy model.
\end{abstract}

Keywords: BEKK model, MGARCH model, structural break, volatility persistence

\section{Introduction}

In recent literature of business, economics, and finance, structural breaks become highly important research topic, while well-known stock return volatility persistence is still important in time-series modeling in many related fields (e.g., Jung and Maderitsch, 2014; Adesina, 2017; Ahmed, 2018). Then how do structural breaks in stock returns affect their volatility persistence? In order to answer this research question, this article quantitatively examines how structural breaks affect the volatility persistence in stock returns by using the US and Japanese stock market index return data.

More specifically, this paper quantitatively inspects the effects of structural breaks in stock returns on their volatility persistence by using the return data of S\&P 500 and Tokyo stock price index (TOPIX) and applying the diagonal Baba-Engle-Kraft-Kroner (BEKK)-multivariate generalized autoregressive conditional heteroscedasticity $(\mathrm{MGARCH})$ model with and without structural break dummies. We note that in the fields of business, economics, and finance, GARCH models are highly important and useful as many extant studies suggested (e.g., Bollerslev, 1986; Nelson, 1991; Engle and Kroner, 1995). As a result of our analyses, we reveal the following interesting findings.

(1) First, we clarify that for both the US and Japanese stock returns, the values of the GARCH parameters, i.e., the values of the volatility persistence parameters in the diagonal BEKK-MGARCH models decrease when we include the structural break dummies in the models. (2) Second, we further reveal that the estimated time-varying volatilities by the diagonal BEKK-MGARCH models with and without structural break dummies are generally similar; however, very interestingly, during the Lehman crisis in 2008 , the derived volatilities from the model with structural break dummies are slightly higher than those from the no structural break dummy model. (3) Third, we furthermore reveal that the estimated time-varying correlations by the diagonal BEKK-MGARCH models with and without structural break dummies are again very similar; however, also very interestingly, the estimated correlations from the no structural break dummy model are slightly higher than those from the structural break dummy model. These interesting findings clarified by this study are the important contributions of this paper. 
As regards the rest of this article, in Section 2, recent related extant studies are reviewed; in Section 3, the data for our study are documented; and in Section 4, the methods for our quantitative analyses are introduced. After these, Sections 5 and 6 describe our results, and Section 7 concludes the paper.

\section{Recent Literature Review}

In this section, recent literature that conducted structural break analyses is briefly reviewed. First, Xing et al. (2012) demonstrated that the credit rating transitions' structural breaks can be well captured by their proposed model, and they showed that structural breaks in credit rating dynamics were different by industries. Berens et al. (2015) showed that the performances of correlation models such as the constant conditional correlation (CCC) model and the dynamic conditional correlation (DCC) model can be improved by taking into consideration structural breaks in asset comovements.

Moreover, El-Shazly (2016) examined the money demand stability and attempted to derive implications for the monetary policy implementations in Egypt by conducting structural break tests, and this study confirmed evidence of the lending using short-term interest rates was the main policy instrument in Egypt. Tsuji (2016a) performed the VECH-, BEKK-, DCC-, and ADCC-MGARCH analyses, and revealed almost perfect correlations around the period of the US Lehman crisis across the US VIX and the volatility forecasts from EGARCH and TGARCH models.

Furthermore, Mensi et al. (2018) investigated the impacts of structural breaks on the long memory of Bitcoin and Ethereum returns, and they identified the dual long memory and structural changes on these returns by GARCH, FIGARCH, FIAPARCH, and HYGARCH models. Finally, Tsuji (2018a) investigated return transmission and volatility spillovers between WTI crude oil futures and international oil equities by applying a new DCC-MEGARCH model, and this study used structural break analyses for the robustness checks. Although univariate analyses, Tsuji (2018b) and Tsuji (2018c) also analyzed the relations between structural breaks in stock returns and their volatility persistence in international stock markets.

As above, in recent business, economics, and finance literature, structural break analyses using MGARCH models are being important. Thus, in this paper, we carefully examine the effects of structural breaks in the US and Japanese stock returns in the framework of MGARCH analyses.

\section{Data}

This section documents our data and variables that we use in this study. All raw price data are from Thomson Reuters. More specifically, our first variable is denoted as LRUS, which is the daily log difference percentage return of the US S\&P 500; and our second variable is denoted as LRJP, which is the daily log difference percentage return of the Japanese TOPIX. Our analyzing sample period of these two return series spans from January 4, 2000 to August 3, 2018.

Figure 1 shows the evolution of the above daily log returns of S\&P 500 (Panel A) and TOPIX (Panel B) from January 4, 2000 to August 3, 2018. Table 1 exhibits the summary statistics of the US and Japanese stock returns. As Table 1 indicates, for both two return series, their mean values take near zero values and their skewness values show negative values. Further, we also understand that their kurtosis values are clearly much higher than three, which is the kurtosis value of normal distributions.

Table 1. Summary statistics of daily log stock returns in the US and Japan

\begin{tabular}{lll}
\hline Statistic & LRUS & LRJP \\
\hline Mean & 0.0138 & 0.0002 \\
Maximum & 10.9572 & 12.8646 \\
Minimum & -9.4695 & -10.0071 \\
Standard deviation & 1.1854 & 1.3391 \\
Skewness & -0.2244 & -0.3659 \\
Excess Kurtosis & 9.0742 & 6.6846
\end{tabular}

Notes: Our analyzing sample period spans from January 4, 2000 to August 3, 2018, and the number of the return observations is 4849 .

\section{Methods}

We next explain our analyzing approach. As documented, in this study, we use the diagonal BEKK-MGARCH model (Engle and Kroner, 1995) for our analyses. Namely, for the US and Japanese stock returns, LRUS and LRJP, this 
study estimates the diagonal BEKK-MGARCH models with and without structural break dummy variables.

More concretely, after we identify their time-series structural break points for LRUS and LRJP by using the iterated cumulative sums of squares (ICSS) algorithm, we construct the structural break dummy variables for each of LRUS and LRJP. The determined structural break point numbers and the time periods are presented in Table 2. As Table 2 suggests, for our full sample period, there exist 12 structural break points for LRUS and there exist seven break points for LRJP. In this paper, we denote the structural break dummy variables for LRUS as $\operatorname{USSB}(m)$; while those for $\operatorname{LRJP}$ as $\operatorname{JPSB}(n)$, and where $m=1, \ldots, 12$, and $n=1, \ldots, 7$.

Hence more specifically, as regards these dummy variables, USSB(1) takes one for January 4, 2000 to June 14, 2002, and zero elsewhere; and USSB(2) takes one for June 17, 2002 to October 17, 2002, and zero elsewhere, for example. Further, JPSB(1) takes one for January 4, 2000 to December 17, 2003, and zero elsewhere; and JPSB(2) takes one for December 18, 2003 to August 9, 2007, and zero elsewhere, for example.

Panel A. S\&P 500

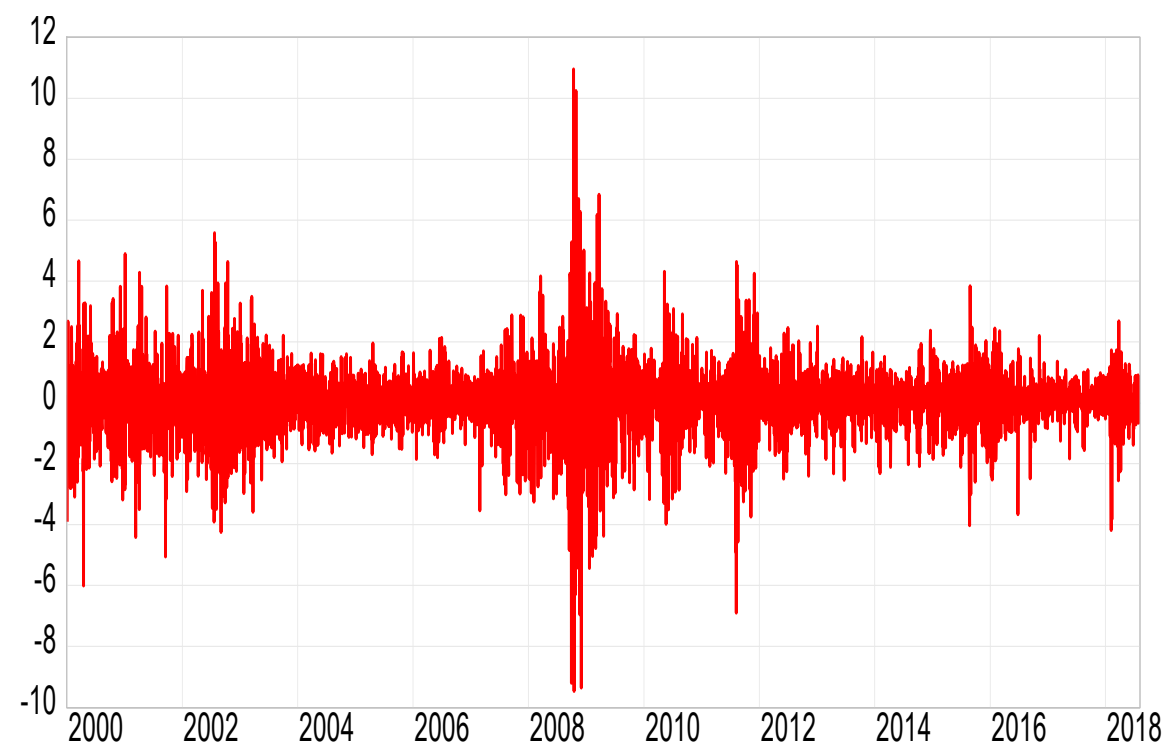

Panel B. TOPIX

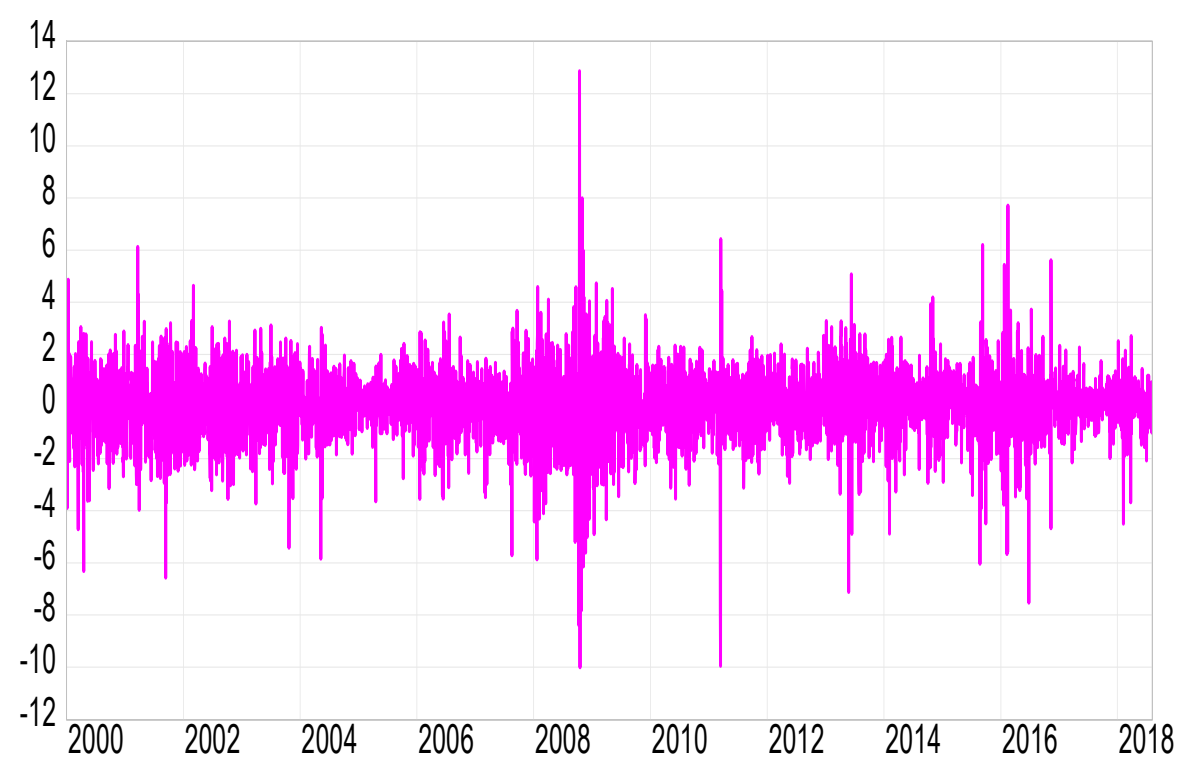

Figure 1. Evolution of daily percentage log returns of the US and Japanese equities 


\section{Model Estimations}

This section explains our results. First, Table 3 provides the estimation results of the diagonal BEKK-MGARCH model for LRUS and LRJP without structural break dummy variable. In our model estimations, only constant terms are employed in the mean (return) equations. In Table 3, Mean (LRUS) and Mean (LRJP) are the constant terms in the mean equations of the US log stock returns and Japanese log stock returns, respectively. Further, $\mathrm{C}(1,1), \mathrm{C}(2,1)$, and $\mathrm{C}(2,2)$ are the constant terms for the variance equations for the US and Japanese log stock returns; $\mathrm{A}(1)$ and $\mathrm{A}(2)$ are the $\mathrm{ARCH}$ parameters; and $\mathrm{B}(1)$ and $\mathrm{B}(2)$ are the GARCH parameters (volatility persistence parameters).

Table 2. Structural breaks for the US and Japanese stock returns

\begin{tabular}{ll}
\hline Panel A. LRUS & Panel B. LRJP \\
\hline \multicolumn{1}{c}{ Structural break point numbers } & \\
\hline \multicolumn{1}{c}{12} & \\
\hline Time periods after considering structural breaks & \\
\hline January 4, 2000 - June 14, 2002 & January 4, 2000 - December 17, 2003 \\
June 17, 2002 - October 17, 2002 & December 18, 2003 - August 9, 2007 \\
October 18, 2002 - April 28, 2003 & August 10, 2007 - September 15, 2008 \\
April 29, 2003 - May 11, 2004 & September 16, 2008 - May 19, 2009 \\
May 12, 2004 - July 9, 2007 & May 20, 2009 - March 14, 2014 \\
July 10, 2007 - September 12, 2008 & March 17, 2014 - August 18, 2015 \\
September 15, 2008 - December 2, 2008 & August 19, 2015 - July 12, 2016 \\
December 3, 2008 - May 18, 2009 & July 13, 2016 - August 3, 2018 \\
May 19, 2009 - September 3, 2010 & \\
September 6, 2010 - August 1, 2011 & \\
August 2, 2011 - December 20, 2011 & \\
December 21, 2011 - June 30, 2016 & \\
July 1, 2016 - August 3, 2018 & \\
\hline
\end{tabular}

Notes: Our analyzing full sample period spans from January 4, 2000 to August 3, 2018, and the number of the return observations for our full sample period is 4849 . Identifications of structural break points are conducted by using the iterated cumulative sums of squares (ICSS) algorithm.

Next, Table 4 provides the estimation results of the diagonal BEKK-MGARCH model for LRUS and LRJP with structural break dummy variables. In Table 4, we again employ only constant terms in the return equations. In Table 4, Mean (LRUS) and Mean (LRJP) are again the constant terms in the mean equations of the US and Japanese log stock returns, respectively. Further, $\mathrm{C}(1,1), \mathrm{C}(2,1)$, and $\mathrm{C}(2,2)$ are again the constant terms for the variance equations for the US and Japanese log stock returns; $\mathrm{A}(1)$ and $\mathrm{A}(2)$ are the $\mathrm{ARCH}$ parameters; and $\mathrm{B}(1)$ and $\mathrm{B}(2)$ are the GARCH parameters (volatility persistence parameters). Moreover, in Table 4, from USSB(1) to USSB(12) are the structural break dummy variables for the US log stock returns; and from JPSB(1) to JPSB(7) are the structural break dummy variables for the Japanese log stock returns.

Comparing the results in Tables 3 and 4, the following is evident. Namely, for LRUS, the GARCH parameter values of the diagonal BEKK-MGARCH model (B(1)) decrease from 0.9574 (Table 3) to 0.8900 (Table 4) when structural break dummies are included. Similarly, for LRJP, the GARCH parameter values of the diagonal BEKK-MGARCH model (B(2)) decrease from 0.9468 (Table 3) to 0.9156 (Table 4) when structural break dummies are included. Thus, our estimation results of the diagonal BEKK-MGARCH models with and without structural break dummy variables demonstrate that when stock return structural breaks are taken into consideration, stock return volatility persistence clearly decreases. In other words, it is generally understood that when structural breaks in stock returns are not taken into account, stock return volatility persistence is overestimated in MGARCH models.

\section{Time-varying Volatilities and Correlations}

We next compute the time-varying volatilities and correlations using the US and Japanese stock returns. Specifically, we derive the time-varying volatilities of the log returns as to the US S\&P 500 and Japanese TOPIX and the time-varying correlation coefficients between them by using the diagonal BEKK-MGARCH models with and without the structural break dummy variables. 
Table 3. Estimation results of the diagonal BEKK-MGARCH model with no structural break dummy variable

\begin{tabular}{lllll}
\hline Variable & Coefficient & Standard error & $t$-statistic & $p$-value \\
\hline Mean(LRUS) & $0.0513 * * *$ & 0.0114 & 4.5011 & 0.0000 \\
Mean(LRJP) & $0.0402 * * *$ & 0.0154 & 2.6115 & 0.0090 \\
$\mathrm{C}(1,1)$ & $0.1102 * * *$ & 0.0095 & 11.5488 & 0.0000 \\
$\mathrm{C}(2,1)$ & $0.0289 * *$ & 0.0114 & 2.5299 & 0.0114 \\
$\mathrm{C}(2,2)$ & $0.1952 * * *$ & 0.0167 & 11.6847 & 0.0000 \\
$\mathrm{~A}(1)$ & $0.2724 * * *$ & 0.0132 & 20.6940 & 0.0000 \\
$\mathrm{~A}(2)$ & $0.2887 * * *$ & 0.0134 & 21.5910 & 0.0000 \\
$\mathrm{~B}(1)$ & $0.9574 * * *$ & 0.0041 & 233.5559 & 0.0000 \\
$\mathrm{~B}(2)$ & $0.9468 * * *$ & 0.0050 & 187.6263 & 0.0000 \\
\hline
\end{tabular}

Log Likelihood $\quad-14285.4247$

Notes: Our sample period spans from January 4, 2000 to August 3, 2018, with 4849 usable return observations.

First, Figure 2 plots the evolution of the daily annualized time-varying volatilities of the US (Panel A) and Japanese (Panel B) stock returns from the diagonal BEKK-MGARCH model with no structural break dummy; while Figure 3 plots those of the US (Panel A) and Japanese (Panel B) stock returns from the diagonal BEKK-MGARCH model with structural break dummies. In Figures 2 and 3, we can see that the estimated volatilities are generally similar; however, it is very interesting to note that during the Lehman crisis in 2008 , the derived volatilities from the model with structural break dummies are slightly higher than those from the no structural break dummy model.

Further, Figure 4 shows the time-varying correlation coefficients between the US and Japanese stock returns from the diagonal BEKK-MGARCH models without and with structural break dummies (Panels A and B, respectively). In Figure 4, the estimated correlations are very similar; however, also interestingly, the estimated correlations from our no structural break dummy model are slightly higher than those from the structural break dummy model.

Table 4. Estimation results of the diagonal BEKK-MGARCH model with structural break dummy variables

\begin{tabular}{lllll}
\hline Variable & Coefficient & Standard error & $t$-statistic & $p$-value \\
\hline Mean(LRUS) & $0.0549 * * *$ & 0.0105 & 5.2370 & 0.0000 \\
Mean(LRJP) & $0.0435^{* * *}$ & 0.0161 & 2.6998 & 0.0069 \\
C(1,1) & $0.2022^{* * *}$ & 0.0176 & 11.5000 & 0.0000 \\
C(2,1) & $0.0356^{* *}$ & 0.0179 & 1.9876 & 0.0469 \\
C(2,2) & $0.2556^{* * *}$ & 0.0240 & 10.6558 & 0.0000 \\
A(1) & $0.2728^{* * *}$ & 0.0155 & 17.6049 & 0.0000 \\
A(2) & $0.2681^{* * *}$ & 0.0151 & 17.7563 & 0.0000 \\
B(1) & $0.8900^{* * *}$ & 0.0139 & 64.2077 & 0.0000 \\
B(2) & $0.9156^{* * *}$ & 0.0104 & 88.1986 & 0.0000 \\
USSB(1)(1,1) & -0.9724 & 2.2743 & -0.4276 & 0.6690 \\
USSB(1)(2,1) & 1.8192 & 1.8515 & 0.9826 & 0.3258 \\
USSB(1)(2,2) & 0.4196 & 2.6339 & 0.1593 & 0.8734 \\
USSB(2)(1,1) & -0.6055 & 2.2786 & -0.2657 & 0.7904 \\
USSB(2)(2,1) & 1.8251 & 1.8532 & 0.9849 & 0.3247 \\
USSB(2)(2,2) & 0.4949 & 2.6350 & 0.1878 & 0.8510 \\
USSB(3)(1,1) & -0.9271 & 2.2748 & -0.4075 & 0.6836 \\
USSB(3)(2,1) & 1.7967 & 1.8522 & 0.9700 & 0.3320 \\
USSB(3)(2,2) & -0.3733 & 2.6290 & -0.1420 & 0.8871 \\
USSB(4)(1,1) & -1.1286 & 2.2730 & -0.4965 & 0.6195 \\
USSB(4)(2,1) & 1.7982 & 1.8507 & 0.9716 & 0.3312 \\
USSB(4)(2,2) & 0.4064 & 2.6336 & 0.1543 & 0.8774 \\
USSB(5)(1,1) & -1.1584 & 2.2725 & -0.5098 & 0.6102
\end{tabular}




\begin{tabular}{|c|c|c|c|c|}
\hline $\operatorname{USSB}(5)(2,1)$ & 1.7403 & 1.8499 & 0.9407 & 0.3468 \\
\hline $\operatorname{USSB}(5)(2,2)$ & 0.3278 & 2.6331 & 0.1245 & 0.9009 \\
\hline $\operatorname{USSB}(6)(1,1)$ & -0.7794 & 2.2714 & -0.3431 & 0.7315 \\
\hline $\operatorname{USSB}(6)(2,1)$ & 1.6711 & 1.8449 & 0.9058 & 0.3650 \\
\hline $\operatorname{USSB}(6)(2,2)$ & 0.4945 & 2.6298 & 0.1880 & 0.8508 \\
\hline $\operatorname{USSB}(7)(1,1)$ & 2.2973 & 1.6312 & 1.4084 & 0.1590 \\
\hline $\operatorname{USSB}(7)(2,1)$ & 0.7925 & 0.9570 & 0.8281 & 0.4076 \\
\hline $\operatorname{USSB}(7)(2,2)$ & 1.7741 & 2.0374 & 0.8708 & 0.3839 \\
\hline $\operatorname{USSB}(8)(1,1)$ & -0.3946 & 1.6021 & -0.2463 & 0.8055 \\
\hline $\operatorname{USSB}(8)(2,1)$ & 0.5720 & 0.9232 & 0.6195 & 0.5356 \\
\hline $\operatorname{USSB}(8)(2,2)$ & 1.1092 & 2.0259 & 0.5475 & 0.5840 \\
\hline $\operatorname{USSB}(9)(1,1)$ & $0.4680 * * *$ & 0.1526 & 3.0673 & 0.0022 \\
\hline $\operatorname{USSB}(9)(2,1)$ & $0.6104 * *$ & 0.2985 & 2.0449 & 0.0409 \\
\hline USSB(9)(2,2) & 0.5287 & 1.8367 & 0.2879 & 0.7735 \\
\hline $\operatorname{USSB}(10)(1,1)$ & $0.3454 * *$ & 0.1497 & 2.3069 & 0.0211 \\
\hline $\operatorname{USSB}(10)(2,1)$ & $0.6246 * *$ & 0.2988 & 2.0901 & 0.0366 \\
\hline $\operatorname{USSB}(10)(2,2)$ & 0.4790 & 1.8366 & 0.2608 & 0.7942 \\
\hline $\operatorname{USSB}(11)(1,1)$ & $0.8088^{* * *}$ & 0.1728 & 4.6803 & 0.0000 \\
\hline $\operatorname{USSB}(11)(2,1)$ & $0.5898^{*}$ & 0.3043 & 1.9385 & 0.0526 \\
\hline $\operatorname{USSB}(11)(2,2)$ & 0.5482 & 1.8372 & 0.2984 & 0.7654 \\
\hline $\operatorname{USSB}(12)(1,1)$ & $0.3113 * *$ & 0.1481 & 2.1016 & 0.0356 \\
\hline $\operatorname{USSB}(12)(2,1)$ & $0.6186^{* *}$ & 0.2955 & 2.0934 & 0.0363 \\
\hline $\operatorname{USSB}(12)(2,2)$ & 0.5311 & 1.8365 & 0.2892 & 0.7724 \\
\hline $\operatorname{JPSB}(1)(1,1)$ & 1.2457 & 2.2722 & 0.5483 & 0.5835 \\
\hline $\operatorname{JPSB}(1)(2,1)$ & -1.7970 & 1.8518 & -0.9704 & 0.3318 \\
\hline $\operatorname{JPSB}(1)(2,2)$ & -0.2537 & 2.6325 & -0.0964 & 0.9232 \\
\hline $\operatorname{JPSB}(2)(1,1)$ & 1.2007 & 2.2723 & 0.5284 & 0.5972 \\
\hline $\operatorname{JPSB}(2)(2,1)$ & -1.7588 & 1.8505 & -0.9505 & 0.3419 \\
\hline $\operatorname{JPSB}(2)(2,2)$ & -0.3098 & 2.6329 & -0.1177 & 0.9063 \\
\hline $\operatorname{JPSB}(3)(1,1)$ & 1.0752 & 2.2688 & 0.4739 & 0.6356 \\
\hline $\operatorname{JPSB}(3)(2,1)$ & -1.6468 & 1.8439 & -0.8931 & 0.3718 \\
\hline $\operatorname{JPSB}(3)(2,2)$ & -0.2343 & 2.6271 & -0.0892 & 0.9289 \\
\hline $\operatorname{JPSB}(4)(1,1)$ & -0.6701 & 1.6009 & -0.4186 & 0.6755 \\
\hline $\operatorname{JPSB}(4)(2,1)$ & -0.6460 & 0.9195 & -0.7026 & 0.4823 \\
\hline $\operatorname{JPSB}(4)(2,2)$ & -0.7843 & 2.0244 & -0.3874 & 0.6985 \\
\hline $\operatorname{JPSB}(5)(1,1)$ & -0.2404 & 0.1482 & -1.6219 & 0.1048 \\
\hline $\operatorname{JPSB}(5)(2,1)$ & $-0.5919 * *$ & 0.2967 & -1.9946 & 0.0461 \\
\hline $\operatorname{JPSB}(5)(2,2)$ & -0.4190 & 1.8364 & -0.2282 & 0.8195 \\
\hline $\operatorname{JPSB}(6)(1,1)$ & $-0.2622 *$ & 0.1485 & -1.7653 & 0.0775 \\
\hline $\operatorname{JPSB}(6)(2,1)$ & $-0.6098 * *$ & 0.2969 & -2.0542 & 0.0400 \\
\hline $\operatorname{JPSB}(6)(2,2)$ & -0.5103 & 1.8366 & -0.2779 & 0.7811 \\
\hline $\operatorname{JPSB}(7)(1,1)$ & -0.1431 & 0.1450 & -0.9872 & 0.3235 \\
\hline $\operatorname{JPSB}(7)(2,1)$ & $-0.5478 *$ & 0.2879 & -1.9029 & 0.0571 \\
\hline $\operatorname{JPSB}(7)(2,2)$ & -0.2556 & 1.8359 & -0.1392 & 0.8893 \\
\hline
\end{tabular}

Notes: Our sample period spans from January 4, 2000 to August 3, 2018, with 4849 usable return observations. 


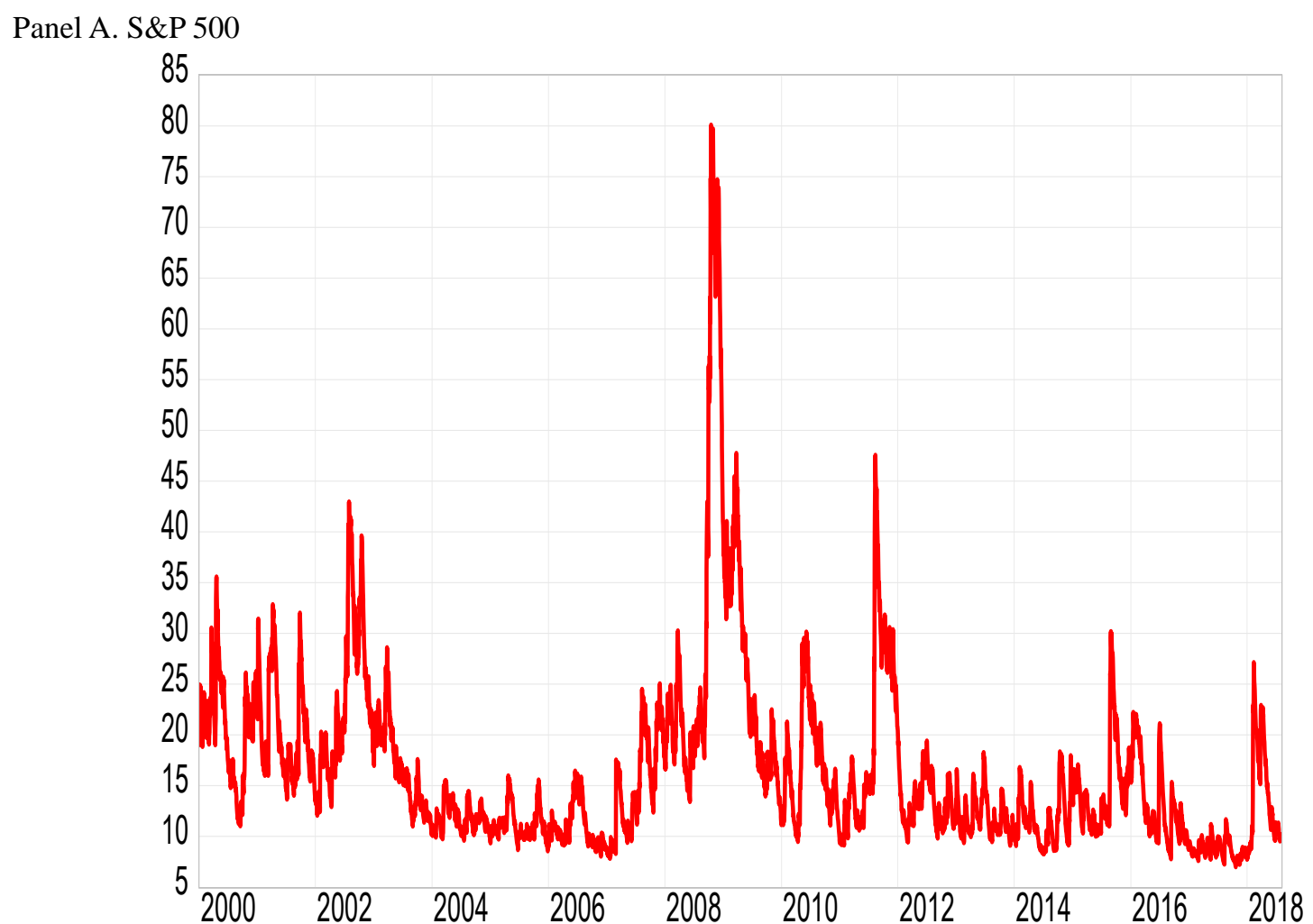

Panel B. TOPIX

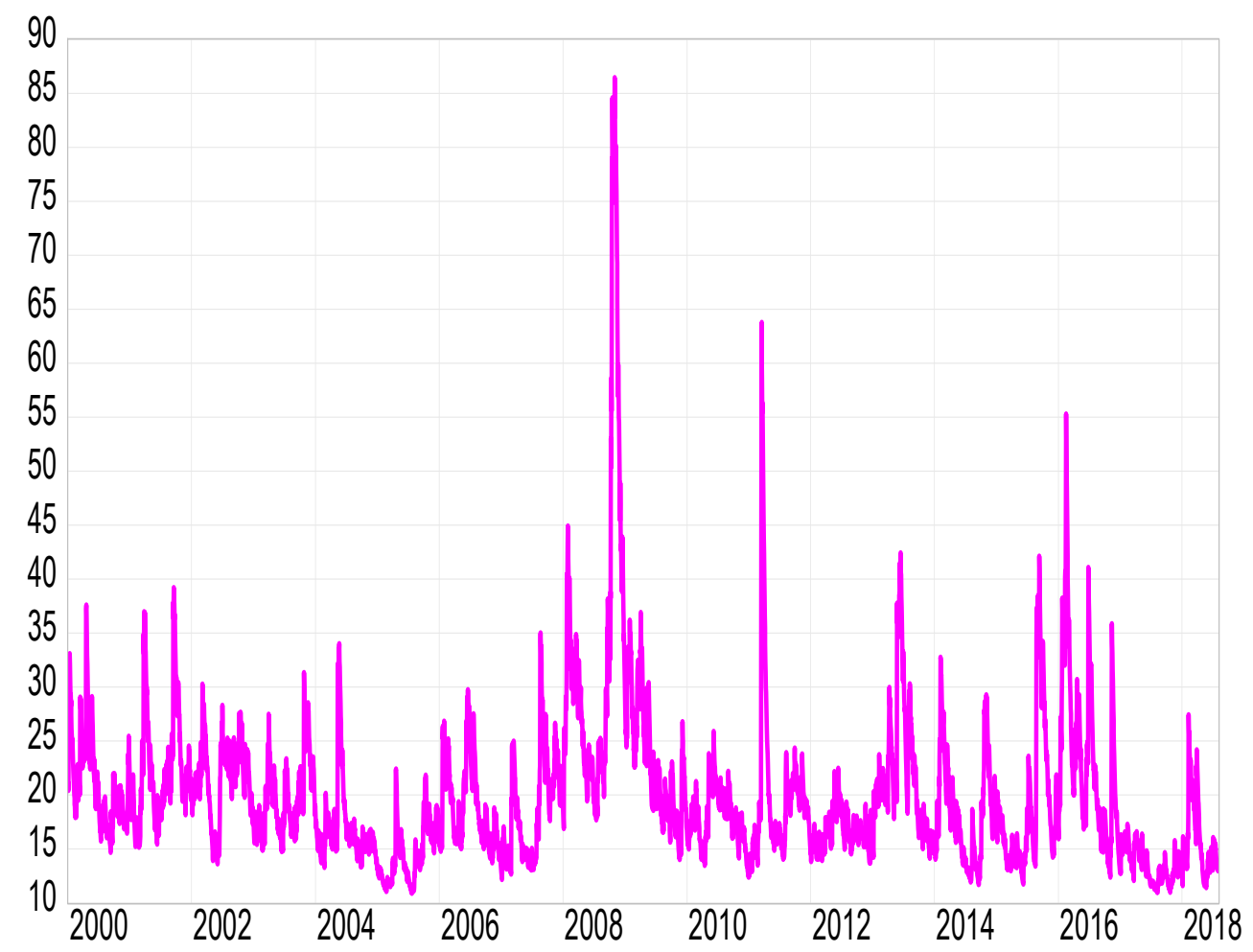

Figure 2. Evolution of the daily annualized time-varying volatilities of the US and Japanese stock returns from the diagonal BEKK-MGARCH model with no structural break dummy 
Panel A. S\&P 500

100

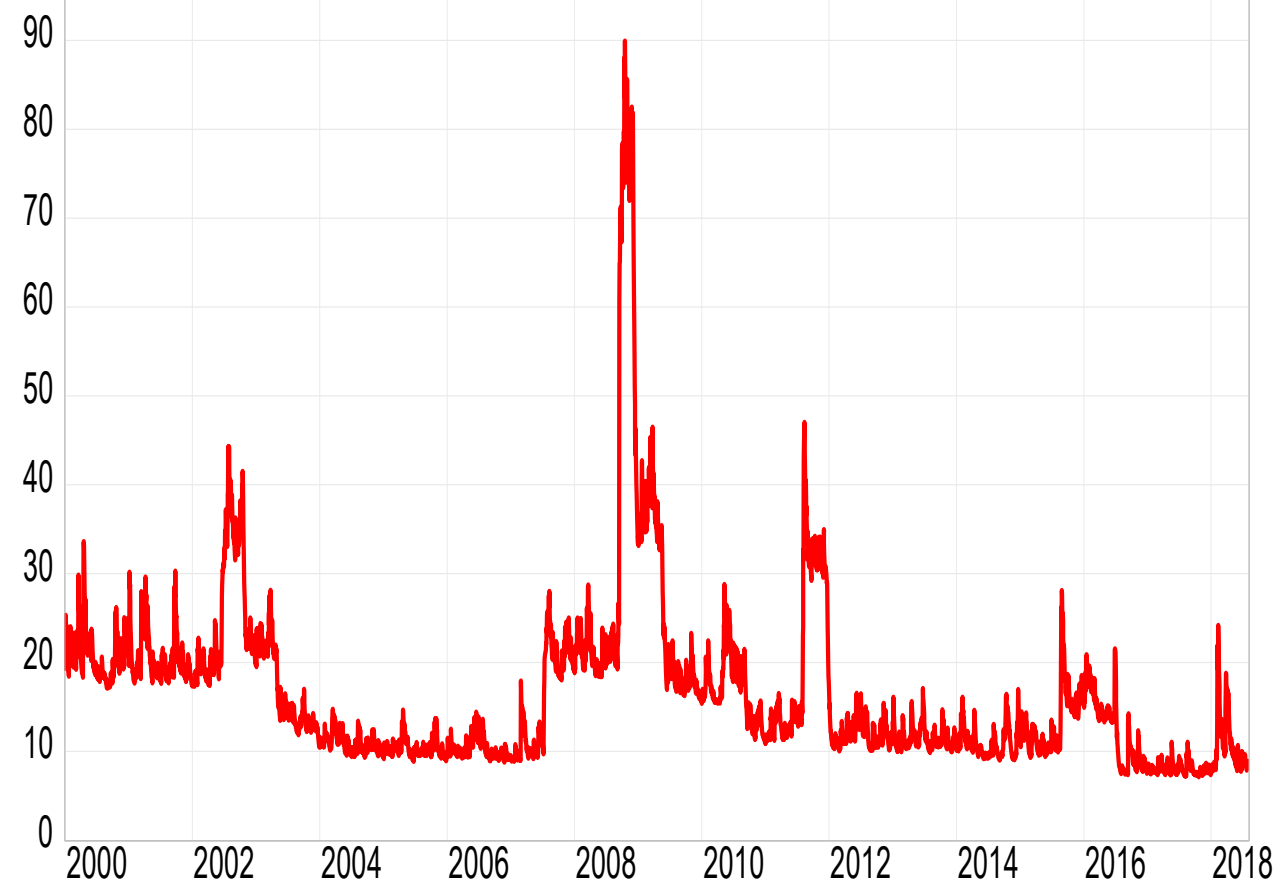

Panel B. TOPIX

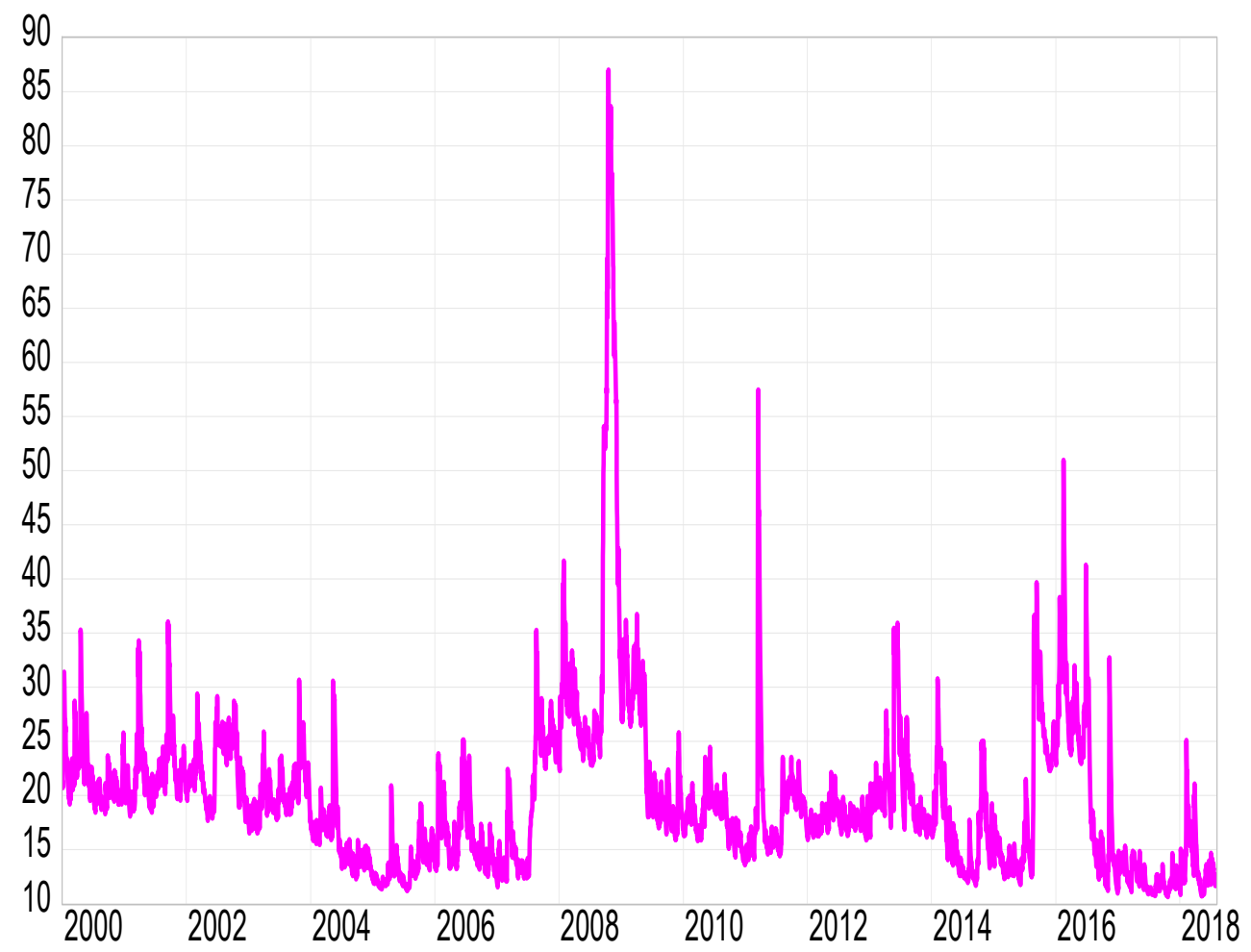

Figure 3. Evolution of the daily annualized time-varying volatilities of the US and Japanese stock returns from the diagonal BEKK-MGARCH model with structural break dummies 
Panel A. Correlations from the model with no structural break dummy

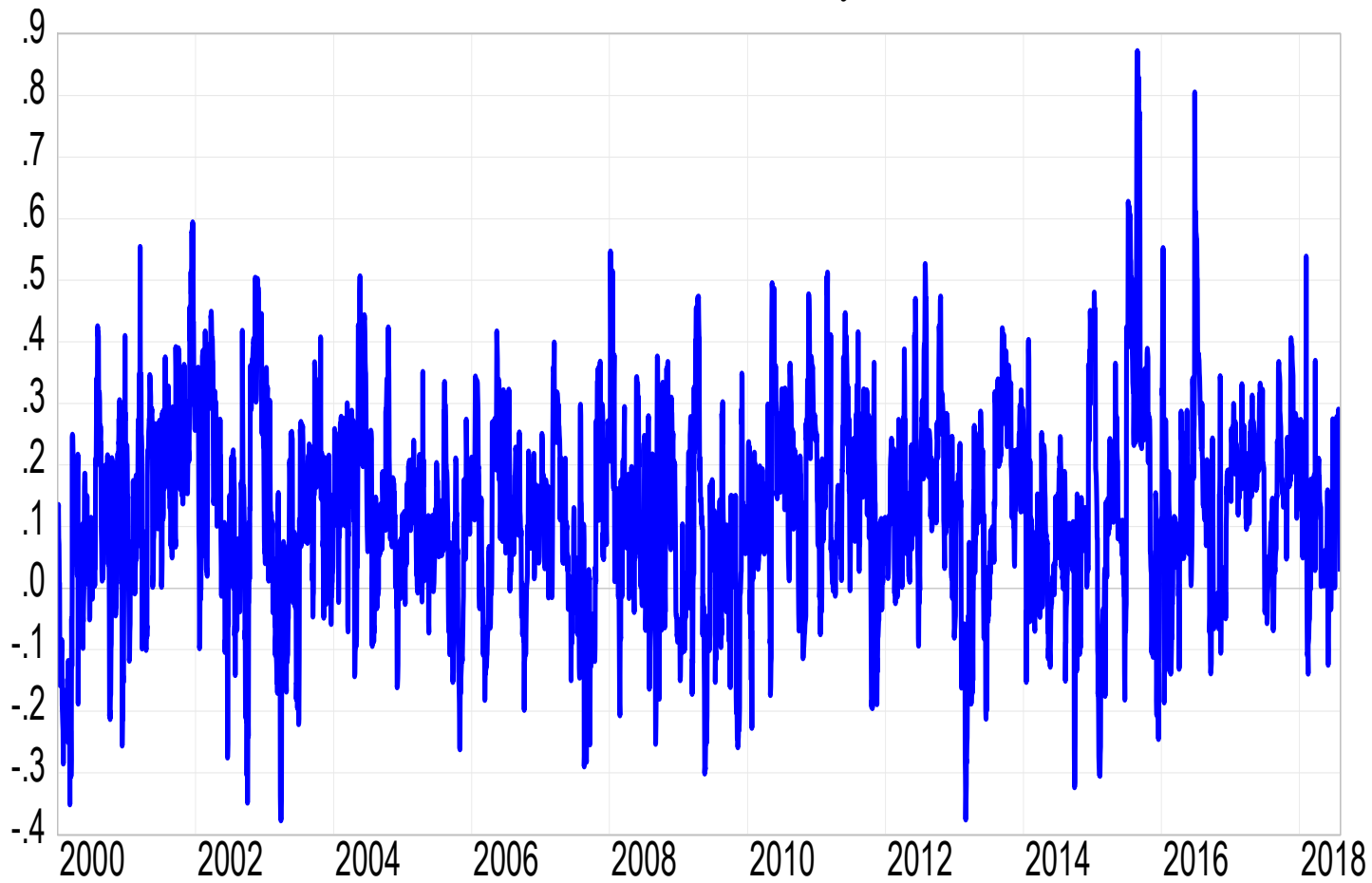

Panel B. Correlations from the model with structural break dummies

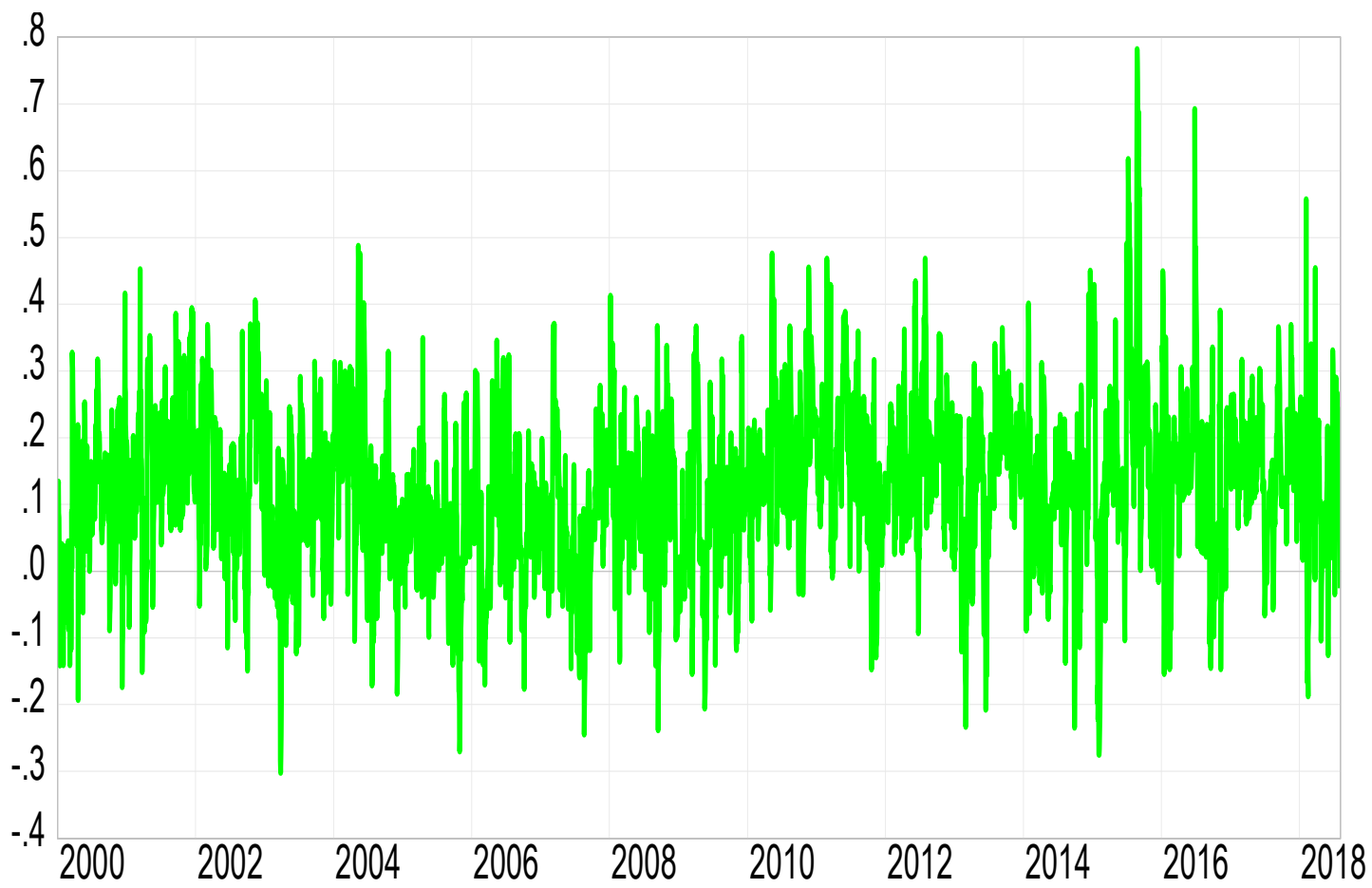

Figure 4. Time-varying correlation coefficients between the US and Japanese stock returns from the diagonal BEKK-MGARCH models

\section{Conclusions}

This paper quantitatively examined the effects of structural breaks in stock returns on their volatility persistence by using the return data of S\&P 500 in the US and TOPIX in Japan. In the fields of business, economics, and finance, it is well-known that GARCH models are highly beneficial and important as Bollerslev (1986), Nelson (1991), Engle 
and Kroner (1995), Tsuji (2016b, 2018d), and numerous other studies suggested. Based on this, applying the diagonal BEKK-MGARCH models with and without structural break dummies, we revealed the following interesting findings.

(1) First, we clarified that for both the US and Japanese stock returns, the values of the GARCH parameters, namely, the values of the volatility persistence parameters in the diagonal BEKK-MGARCH models decreased when we incorporate the structural break dummies into the model. This result is consistent with the finding by Ewing and Malik (2016), for instance.

(2) Second, we further found that the estimated time-varying volatilities by the diagonal BEKK-MGARCH models with and without structural break dummies were generally similar; however, very interestingly, during the Lehman crisis in 2008 , the derived volatilities from the model with structural break dummies were slightly higher than those from the no structural break dummy model.

(3) Third, we furthermore uncovered that the estimated time-varying correlations by the diagonal BEKK-MGARCH models with and without structural break dummies were very similar; however, also very interestingly, the estimated correlations from the no structural break dummy model were slightly higher than those from the structural break dummy model.

Furthermore, adding some implications from our results for business and management, it is highly important to estimate asset return volatilities very accurately as also demonstrated by Tsuji (2016a). Specifically, for downside risk management in all firms in the world, volatilities of asset returns are vital since volatility is a key parameter of computing, for example, the Value at Risk, which is one of the most important measures of downside risk for all firms. Further, Tsuji (2018b) demonstrated that in considering volatility spillovers, downside risk is highly important because volatility spillovers are often tied to the well-known leverage effect. Moreover, Tsuji (2018b) also indicated that we can interpret the mutual asymmetric volatility spillovers evidenced in the study as the bidirectional spillovers of downside risk in international oil and equity markets. Hence, for all firms, to properly manage their downside risk, we again note that by taking the volatility spillover effects and the structural breaks in asset returns into account, to estimate asset return volatilities much accurately is very crucial as our present study suggested.

As above, according to our empirical results, we understand that when structural breaks in stock returns are not taken into account, volatility persistence of international stock returns may be overestimated in GARCH models. Further, our results also suggested that the estimated time-varying volatilities and correlations became different when structural breaks in stock returns are taken into consideration. It is also noted that the time-series modeling demonstrated in this paper can be widely applied to many other time-series data in the fields of business, economics, and finance; and thus, further detailed quantitative research considering structural breaks in multivariate time-series data is needed. This line of research is one of our important future tasks.

\section{Acknowledgements}

The author firstly appreciates this journal for its repeated kind invitation to write to the journal. The author also highly appreciates Jenny Zhang for her kind editorial support to this paper. Moreover, the author thanks an editor of this journal and an anonymous referee for their constructive and supportive comments on this paper. Furthermore, the author also greatly appreciates the Chuo University Grant for Special Research for the generous financial support to this research. Finally, I deeply thank all the Editors of this journal for their kind attention to my paper.

\section{References}

Adesina, T. (2017). Estimating volatility persistence under a Brexit-vote structural break. Finance Research Letters, 23, 65-68. https://doi.org/10.1016/j.frl.2017.03.004

Ahmed, W.M.A. (2018). On the interdependence of natural gas and stock markets under structural breaks. The Quarterly Review of Economics and Finance, 67, 149-161. https://doi.org/10.1016/j.qref.2017.06.003

Berens, T., Weiß, G.N.F., \& Wied, D. (2015). Testing for structural breaks in correlations: Does it improve Value-at-Risk forecasting? Journal of Empirical Finance, 32, 135-152. http://dx.doi.org/10.1016/j.jempfin.2015.03.001

Bollerslev, T. (1986). Generalized autoregressive conditional heteroscedasticity. Journal of Econometrics, 31, 307-327. https://doi:10.1016/0304-4076(86)90063-1

El-Shazly, A. (2016). Structural breaks and monetary dynamics: A time series analysis. Economic Modelling, 53, 133-143. http://dx.doi.org/10.1016/j.econmod.2015.11.019

Engle, R.F., \& Kroner, K.F. (1995). Multivariate simultaneous generalized Arch. Econometric Theory, 11, 122-150. 
https://doi.org/10.1017/S0266466600009063

Ewing, B.T., \& Malik, F. (2016). Volatility spillovers between oil prices and the stock market under structural breaks. Global Finance Journal, 29, 12-23. http://dx.doi.org/10.1016/j.gfj.2015.04.008

Jung, R.C., \& Maderitsch, R. (2014). Structural breaks in volatility spillovers between international financial markets: Contagion or mere interdependence? Journal of Banking \& Finance, 47, 331-342. https://doi.org/10.1016/j.jbankfin.2013.12.023

Mensi, W., Al-Yahyaee, K.H., \& Kang, S.H. (2018). Structural breaks and double long memory of cryptocurrency prices: A comparative analysis from Bitcoin and Ethereum. Finance Research Letters, forthcoming. https://doi.org/10.1016/j.frl.2018.07.011

Nelson, D.B. (1991). Conditional heteroskedasticity in asset returns: A new approach. Econometrica, 59, 347-370. https://doi.org/10.2307/2938260

Tsuji, C. (2016a). Does the fear gauge predict downside risk more accurately than econometric models? Evidence from the US stock market. Cogent Economics \& Finance, 4, 1220711. http://dx.doi.org/10.1080/23322039.2016.1220711

Tsuji, C. (2016b). Effects of the Japanese stock market on Canadian value stocks. Journal of Management and Strategy, 7, 21-30. https://doi.org/10.5430/jms.v7n2p21

Tsuji, C. (2018a). Return transmission and asymmetric volatility spillovers between oil futures and oil equities: New DCC-MEGARCH analyses. Economic Modelling, 74, 167-185. https://doi.org/10.1016/j.econmod.2018.05.007

Tsuji, C. (2018b). New DCC analyses of return transmission, volatility spillovers, and optimal hedging among oil futures and oil equities in oil-producing countries. Applied Energy, 229, 1202-1217. https://doi.org/10.1016/j.apenergy.2018.08.008

Tsuji, C. (2018c). How are structural breaks related to stock return volatility persistence? Evidence from China and Japan. Modern Economy, 9, 1635-1643. https://doi.org/10.4236/me.2018.910102

Tsuji, C. (2018d). Structural breaks and volatility persistence of stock returns: Evidence from the US and UK equity markets. Applied Economics and Finance, 5, 76-83. https://doi.org/10.11114/aef.v5i6.3690

Xing, H., Sun, N., \& Chen, Y. (2012). Credit rating dynamics in the presence of unknown structural breaks. Journal of Banking \& Finance, 36, 78-89. http://dx.doi.org/10.1016/j.jbankfin.2011.06.005 